\title{
Epidemiologic analysis of prevalence of the hyperhidrosis*
}

\author{
Fernanda Alvarenga Estevan ${ }^{1}$ \\ Nelson Wolosker ${ }^{2,3}$
}

\author{
Marina Borri Wolosker ${ }^{1}$ \\ Pedro Puech-Leão ${ }^{2}$
}

DOI: http:/ / dx.doi.org/10.1590/abd1806-4841.20175551

\begin{abstract}
BACKGROUND: The present paper aims to study the prevalence of the various manifestations of hyperhidrosis in patients who sought treatment in a specialized ambulatory in the state of São Paulo.

Овлестіvеs: Opposite to previous studies, this paper studies the different combinations of sweating sites, not being restricted to the main complaint site of the patients, but taking into consideration secondary complaints patients may present.

METHODS: This was a retrospective approach of a database containing more than 1200 patients in which were mapped: combination of sweating sites, age of onset, age spectrum, mean age, body mass index and gender of patients. Patients were categorized into four groups based on their main sweating site - palmar, plantar, axillary and facial.

RESULTS: We concluded that hyperhidrosis appears frequently in more than one site, being the main complaint that affects the most patients palmar hyperhidrosis, which appears early in the patients during adolescence. When there are two sites of sweating, the most frequent combination is palmar + plantar, and when there are three sites of sweating the most frequent combinations are palmar + plantar + axillary and axillary + palmar + plantar.

StUdy Limitations: This research has casuistics limited to a single care service for patients with hyperhidrosis.

CONCLUSION: It is necessary to keep in mind that the disease manifests itself mainly in more than one location, with different intensities in each of the patients, generating a significant impairment of their quality of life.
\end{abstract}

Keywords: Hyperhidrosis; Epidemiology; Sweating; Prevalence

\section{INTRODUCTION}

Hyperhidrosis $(\mathrm{HH})$ is a disease characterized by excessive sweating - in addition to the physiologically necessary - which occurs mainly in the palms of the hands, armpits, soles and face, but can also affect the abdomen, chest, back, inguinal regions and lower limbs. ${ }^{1,2} \mathrm{HH}$ has an unknown etiology and is associated with intense emotional, occupational and social stress. It usually begins in childhood or adolescence and entails an important impairment in the quality of life of individuals who have it. ${ }^{3}$

Studies from several parts of the world have been addressing the epidemiology of $\mathrm{HH}$, but in most of them a limited portion of populations has been analyzed, thus their conclusions cannot be generalized. ${ }^{4-7}$ In almost all of these studies, only the analysis of the site of major relevance of sweating is verified, not considering other possible associated sweating sites.

Park et al., in 2010, at the HH Center at Ajou University Hospital in South Korea, found that most patients had $\mathrm{HH}$ in two or more sites and were the first group to analyze not only the main site, but all the sites of each patient, observing a prevalence of $32.2 \%$ of palmoplantar $\mathrm{HH}$ and $22.4 \%$ of axillary-palmoplantar $\mathrm{HH}^{8}$
Bragança et al., in 2014, studying the relationship between anxiety and depression in individuals with $\mathrm{HH}$, observed that, of $197 \mathrm{HH}$ patients who sought treatment at a specialized outpatient clinic in the city of Aracaju, the majority (78.1\%) presented $\mathrm{HH}$ in more than one site. ${ }^{9}$

Considering the small number of articles and analyzing the distributions of $\mathrm{HH}$, the present research aims, in an unprecedented manner in Brazil, to analyze the different presentations of $\mathrm{HH}$ (all $\mathrm{HH}$ sites) in a large number of patients $(1,278)$ with $\mathrm{HH}$, considering all $\mathrm{HH}$ sites of individuals who sought assistance in a specialized outpatient clinic for treatment of $\mathrm{HH}$ in a period of seven years.

\section{METHODS}

A retrospective analysis of 1,278 $\mathrm{HH}$ patients was conducted in an outpatient clinic specialized in the treatment of $\mathrm{HH}$ from August 2007 to July 2014. This study was approved by the institution's Research Ethics Committee.

Patients were divided into four groups, based on the main site of $\mathrm{HH}$ (point of greatest interference defined by the patient):

\footnotetext{
Received on 06.01.2016.

Approved by the Advisory Board and accepted for publication on 10.07.2016.

Study conducted at Clinics Hospital of the School of Medicine of the Universidade de São Paulo (HCFMUSP) and Hospital Israelita Albert Einstein - São Paulo (SP), Brazil.

Financial support: None

Conflict of interest: None.

School of Medicine of the Universidade de São Paulo (FMUSP) - São Paulo (SP), Brazil.

Department of Surgery - Division of Vascular and Endovascular Surgery of the Clinics Hospital of the School of Medicine of the Universidade de São Paulo (HCFMUSP) - São Paulo (SP), Brazil.

Department of Vascular and Endovascular Surgery of the Hospital Israelita Albert Einstein - São Paulo (SP), Brazil.
}

C2017 by Anais Brasileiros de Dermatologia 
palmar, when the main complaint was $\mathrm{HH}$ in the palms of the hands; plantar, when on the feet; axillary when in armpits; and facial when on the face.

For each group, gender, age at first visit, age at first disease manifestation, body mass index (BMI), previous treatments, number of secondary points of $\mathrm{HH}$, and associations between these points were analyzed.

Within each group, two subgroups were analyzed more closely. The first, patients who had a single site of sweating in addition to the main one (total of two sites), and the second, patients who had two other sites of sweating in addition to the main one (total of three sites).

Associations between sweating sites most frequently found were listed in the tables.

\section{Statistical analyzes}

Descriptive Analysis

Descriptive analyzes for the quantitative data were performed presenting medians (for age and BMI) and arithmetic means (for other data) accompanied by the respective percentiles. Qualitative variables were presented in frequency tables.

Inferential Analysis

Kruskal-Wallis test was used for the following variables: age and BMI. Chi-square test was used for the proportions of gender and onset phase.

A probability of error of type I $(\alpha)$ of 0.05 was considered in all inferential analyzes.

SPSS program, version 17, was used for statistical analysis.

\section{RESULTS}

The demographic data of patients are presented in table 1. Analyzing the main complaints within each gender, we ob- served that, in both genders, the most prevalent complaints were palmar $\mathrm{HH}(48.0 \%$ in both genders) and axillary $\mathrm{HH}(36.2 \%$ in women and $36.6 \%$ in men), which appear in similar frequencies. Analyzing genders within the main complaints, it is observed that, regardless of the main complaint, women have a higher prevalence of cases in relation to men.

We found that the majority of $\mathrm{HH}$ cases occur in individuals with a median age of less than 30 years, with the exception of facial $\mathrm{HH}$, which appears in individuals with a mean age of 42 years.

Comparing medians of age among the four groups, there was no significant difference between the medians of age between the axillary and plantar main complaint groups $(p=0.49)$. The other groups presented significant difference $(p=0.001)$.

It is also observed the predominance of a normal BMI in patients with $\mathrm{HH}$, with the exception of patients with facial $\mathrm{HH}$ who have a high BMI (29.0). In addition, all groups presented different mean BMI ( $p=0.001)$, with the exception of the axillary and plantar groups, which presented a similar mean BMI $(p=0.43)$.

Most patients with axillary, plantar and facial $\mathrm{HH}$ have a greater tendency to present the first manifestation of the disease in childhood, whereas patients with palmar $\mathrm{HH}$ present the first manifestation in the period of adolescence.

Ratio of number of complaints presented by patients beyond the relationship between the main site of sweating and the amount of other complaints reported by the patients are shown in table 2 .

Most of patients reported mainly two $(35.2 \%)$ or three $(32.9 \%)$ sweating sites. Only $15 \%$ of patients presented a single site of excessive sweating.

It can be observed that palmar and axillary $\mathrm{HH}$ constitute most of reported main complaints (48.1\% and $36.1 \%$, respectively). We observed that patients whose main complaint was palmar or

\begin{tabular}{|c|c|c|c|c|c|c|c|}
\hline & & Plantar & Facial & Axillary & Palmar & Total & $P$ value \\
\hline Men & & $12(14.4 \%)$ & $52(44.0 \%)$ & $149(32.2 \%)$ & $197(32.0 \%)$ & 410 & \multirow{2}{*}{0.001} \\
\hline Women & & $71(85.6 \%)$ & $66(56.0 \%)$ & $313(67.8 \%)$ & $418(68.0 \%)$ & 868 & \\
\hline \multirow[t]{3}{*}{ Age range } & $\begin{array}{l}\text { Less than or equal to } \\
25 \text { years }\end{array}$ & $37(44.5 \%)$ & $15(12.7 \%)$ & $185(40.0 \%)$ & $401(65.2 \%)$ & 638 & \\
\hline & $\begin{array}{c}\text { Between } 25 \text { and } 50 \\
\text { years }\end{array}$ & $41(49.3 \%)$ & $68(57.6 \%)$ & $263(56.9 \%)$ & $207(33.6 \%)$ & 579 & \\
\hline & $\begin{array}{l}\text { Greater than or } \\
\text { equal to } 50 \text { years }\end{array}$ & $5(1.0 \%)$ & $35(29.6 \%)$ & $14(3.0 \%)$ & $7(1.1 \%)$ & 61 & \\
\hline \multicolumn{2}{|c|}{ Median age } & $26(19-32)$ & $42(31-52)$ & $27(21-34)$ & $22(16-29)$ & & 0.001 \\
\hline \multirow{3}{*}{$\begin{array}{l}\text { Body mass index } \\
\text { (BMI) }\end{array}$} & Less than 18.5 & $6(7.2 \%)$ & 0 & $26(5.6 \%)$ & $65(10.5 \%)$ & 97 & \\
\hline & $\begin{array}{c}\text { Between } 18.5 \text { and } \\
24.9\end{array}$ & $45(54.2 \%)$ & $21(17.7 \%)$ & $291(62.9 \%)$ & $398(64.7 \%)$ & 755 & \\
\hline & Greater than 24.9 & $32(38.5 \%)$ & $97(82.2 \%)$ & $145(31.3 \%)$ & $152(24.7 \%)$ & 426 & \\
\hline \multicolumn{2}{|c|}{ Median BMI } & $23.5(20.3-26.2)$ & $28.3(31-31.1)$ & $23.4(21.5-26.1)$ & $22.4(20-24.9)$ & & 0.001 \\
\hline \multirow[t]{3}{*}{ Time of appearance } & Childhood & $32(38.5 \%)$ & $74(62.7 \%)$ & $383(82.9 \%)$ & $214(34.7 \%)$ & 703 & \multirow{3}{*}{0.001} \\
\hline & Adolescence & $24(28.9 \%)$ & $31(26.2 \%)$ & $74(16.0 \%)$ & $350(56.9 \%)$ & 479 & \\
\hline & Adulthood & $27(32.5 \%)$ & $13(11.0 \%)$ & $5(1.0 \%)$ & $51(8.2 \%)$ & 96 & \\
\hline
\end{tabular}

Chi-Square; Kruskal-Wallis 
TABLE 2: Number of complaints associated with main complaints in each group

\begin{tabular}{|c|c|c|c|c|c|}
\hline Number of other complaints & & $\mathrm{Ma}$ & & & $T$ \\
\hline & Palmar & Axillary & Facial & Plantar & 10 dad \\
\hline 1 & $11(1.7 \%)$ & $140(30.3 \%)$ & $31(26.2 \%)$ & $10(12.0 \%)$ & $192(15.0 \%)$ \\
\hline 2 & $286(46.5 \%)$ & $106(22.9 \%)$ & $24(20.3 \%)$ & $34(40.9 \%)$ & $450(35.2 \%)$ \\
\hline 3 & $225(36.6 \%)$ & $138(29.8 \%)$ & $32(27.1 \%)$ & $26(31.3 \%)$ & $421(32.9 \%)$ \\
\hline 4 & $73(11.9 \%)$ & $44(9.5 \%)$ & $20(16.9 \%)$ & $8(9.6 \%)$ & $145(11.3 \%)$ \\
\hline 5 & $20(3.3 \%)$ & $19(4.1 \%)$ & $4(2.5 \%)$ & $1(1.2 \%)$ & $44(3.4 \%)$ \\
\hline 6 or + & 0 & $15(3.2 \%)$ & $7(5.9 \%)$ & $4(4.8 \%)$ & $26(2 \%)$ \\
\hline Total Partial & $615(48.1 \%)$ & $462(36.1 \%)$ & $118(9.2 \%)$ & $83(6.5 \%)$ & $1278(100.0 \%)$ \\
\hline
\end{tabular}

TABLE 3: Analysis of the relations between primary and secondary complaints of patients with two sites of sweating

Secondary complaint

Main complaint

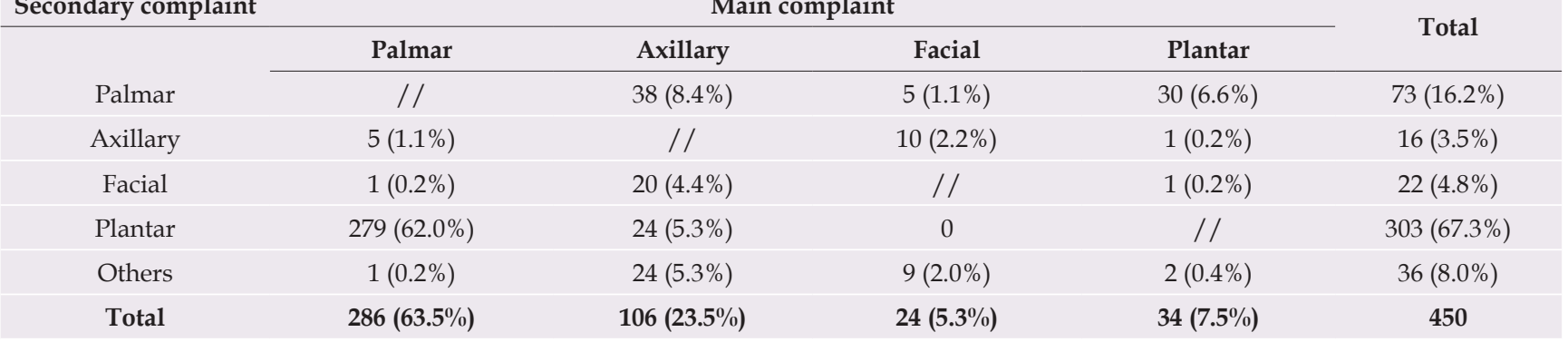

TABLE 4: List of combinations of sweating sites among patients with three complaints

\begin{tabular}{|cc|}
\hline Combination & Frequency \\
\hline palmar/plantar/ axillary & $192(55.5 \%)$ \\
\hline axillary / palmar/plantar & $88(25.4 \%)$ \\
\hline plantar/palmar/ axillary & $18(5.2 \%)$ \\
\hline palmar/plantar/facial & $12(3.4 \%)$ \\
\hline facial/ back/chest & $10(2.9 \%)$ \\
\hline axillary / palmar/facial & $8(2.3 \%)$ \\
\hline facial/palmar/ axillary & $6(1.7 \%)$ \\
\hline axillary / back/facial & $5(1.4 \%)$ \\
\hline facial/back/ axillary & $5(1.4 \%)$ \\
\hline plantar/palmar/facial & $2(0.5 \%)$ \\
\hline Total & 346 \\
\hline
\end{tabular}

plantar $\mathrm{HH}$ had a greater tendency to present one to two associated sweating sites. On the other hand, patients who have as main complaint axillary or facial $\mathrm{HH}$ had none, one or two associated sweating sites, in addition to the main complaint.

Table 3 lists patients with only two sites of sweating: the main site and the secondary site.

Main primary complaint in this group of patients was palmar $\mathrm{HH}(63.5 \%)$, and the main secondary complaint was plantar HH $(67.3 \%)$.

Palmoplantar complaint was the most frequent $(62.0 \%)$, followed by axillary-palmar (8.4\%) and plantar-palmar (6.6\%).

Of the 421 patients with three complaints, we found that 10 main combinations stood out, being present in 346 patients $(82.0 \%)$. Table 4 lists these 10 main combinations.
The majority of patients complaining at three sites (32.9\%) have two more frequent manifestations $(80.9 \%)$ : palmar + plantar + axillary combination (55.5\%) and axillary + palmar + plantar combination $(25.4 \%)$.

\section{DISCUSSION}

From previous studies, it is observed that $\mathrm{HH}$ is a very frequent disease. Prevalence found in these studies range from $0.6 \%$ to $16.3 \%$.

In Brazil, only three epidemiological studies on $\mathrm{HH}$ were conducted.

Felini et al., in 2009, studied the prevalence of $\mathrm{HH}$ among 500 individuals randomly selected in the city of Blumenau. ${ }^{10}$ They verified, based on the answers of a questionnaire responded by the interviewees, a prevalence of $9.0 \%$ for $\mathrm{HH}$.

Westphal et al., in 2011, studied the incidence of HH among 293 students of the Faculty of Medicine of the Universidade Federal do Amazonas (UFAM), in which a prevalence of $5.5 \%$ was found. ${ }^{11}$

Lima et al., in 2015, studied the incidence of HH among 831 medical students in Sergipe, with a prevalence of $14.7 \%{ }^{12}$

In view of this high prevalence of the disease and the availability of effective therapeutic alternatives in recent years, we have observed an increase in the demand for treatments in specialized outpatient clinics. In the outpatient clinic of the Clinics Hospital of FMUSP, approximately five new patients are treated weekly.

There are two main treatments for $\mathrm{HH}$. The first is thoracic sympathectomy, a low risk surgery with high success rate, but that generates compensatory $\mathrm{HH}$ in almost all patients to a greater or lesser degree. ${ }^{1,13}$ The second one is drug therapy with oxybutynin hydrochloride, an antimuscarinic drug that has been shown to be a good treatment alternative for $\mathrm{HH}$ in all its manifestations. ${ }^{14}$ Stud- 
ies have shown that patients who receive oxybutynin as a form of treatment have improved quality of life both in the short and in the long term in all major sites (palmar, facial, plantar and axillary) and also in unusual places (such as back and inguinal regions). ${ }^{15-19}$ Its main adverse event is dry mouth, an uncomfortable event that rarely leads the patient to abandon the treatment. Besides these two alternatives, it is also worth mentioning topical dermatological treatments and the use of botulinum toxin. ${ }^{14}$

Similarly, in literature, we observed that more than twice as many women seek treatment in our outpatient clinic compared with men. This is explained by the greater aesthetic social pressure suffered by female patients, which leads them to seek specialized help sooner and more frequently. ${ }^{20}$ Even so, when it comes to the patient's gender, there is no difference in the effectiveness of the main treatments. ${ }^{20,21}$

Regarding the age group, the majority of $\mathrm{HH}$ cases occur in younger individuals (20 to 30 years old), with the exception of facial $\mathrm{HH}$, which affects individuals with a mean age over 40 years. Analyzing the age spectrum of the patients treated at the outpatient clinic, we verified that patients with palmar $\mathrm{HH}$ are below 25 years of age, while patients with other $\mathrm{HH}$ manifestations are between 25 and 50 years of age.

When analyzing the time of onset of $\mathrm{HH}$ in these individuals, we found that axillary, plantar and facial $\mathrm{HH}$ had their onset during childhood, whereas palmar $\mathrm{HH}$ appeared for the first time in adolescence.

Age of patient does not interfere either in the indication or in the results of the different types of treatment, having good results in children and also in individuals over 40 years. ${ }^{17,22-24}$

Patients with palmar, axillary and plantar $\mathrm{HH}$ have normal BMI, whereas more than $80 \%$ of patients with facial HH have a BMI greater than 25. Surgical treatment is contraindicated in individuals with a BMI greater than 25 due to the increased risk of severe compensatory $\mathrm{HH}$; however, high BMI does not affect drug treatment with oxybutynin hydrochloride. ${ }^{11,25,26,27}$

Similarly to Park et al. ${ }^{8}$ and Bragança et al., ${ }^{9}$ we found that most patients had more than one $\mathrm{HH}$ site $(85 \%)$. We observed that
$68.1 \%$ of the patients analyzed had one to two $\mathrm{HH}$ sites, in addition to the site of main sweating.

Among patients with two $\mathrm{HH}$ sites, the palmar + plantar combination is the most frequently reported $(62.0 \%)$, followed by axillary + palmar $(8.4 \%)$ and plantar + palmar $(6.6 \%)$ combination.

In patients presenting three $\mathrm{HH}$ sites, there is a huge variety of possible combinations. In our study, we related the 10 most frequently encountered combinations, which in turn represent $82 \%$ of the total of these alterations, among them, the most common were palmar + plantar + axillary (55.5\%) and axillary + palmar + plantar $(25.4 \%)$.

This whole range of different forms of presentation of the disease demonstrates that when studying or treating $\mathrm{HH}$, one should not only think of sweating site, as most of the studies published so far have done. It should be borne in mind that the disease manifests itself in more than one site, with different intensities in each of them and in all its presentations, generating a significant impairment of patients' quality of life.

In a patient with $\mathrm{HH}$ only in the hands, surgical treatment by sympathectomy with resection of the fourth thoracic ganglion is considered a great alternative; however, if the patient has palmar and facial $\mathrm{HH}$, management should be resection of the second thoracic ganglion, which greatly increases the risk of severe compensatory hyperhidrosis. In cases where the patient has more than four sites of sweating, surgical treatment will probably also generate a greater chance of compensatory hyperhidrosis. Thus, it is important, for treatment selection, to assess the actual combination of patient sweating sites, rather than just the location of the primary complaint.

\section{CONCLUSION}

$\mathrm{HH}$ manifests itself more frequently in more than one site, and the main complaint that most affects the patients is the palmar, which appears already in the adolescence.

When there are two sweating sites, the most frequent combination is palmar + plantar, and when there are three sites of sweating, the most frequent combinations are: palmar + plantar + axillary and axillary + palmar + plantar. $\square$ 


\section{REFERENCES}

1. Teivelis MP, Varella AY, Wolosker N. Expanded level of sympathectomy and incidence or severity of compensatory hyperhidrosis. J Thorac Cardiovasc Surg. 2014;148:2443-4.

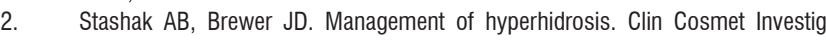
Dermatol. 2014;7:285-99.

3. de Campos JR, Kauffman P, Werebe Ede C, Andrade Filho LO, Kusniek S, Wolosker $\mathrm{N}$, et al. Quality of life, before and after thoracic sympathectomy: report on 378 operated patients. Ann Thorac Surg. 2003;76:886-91.

4. Adar R, Kurchin A, Zweig A, Mozes M. Palmar hyperhidrosis and its surgical treatment: a report of 100 cases. Ann Surg. 1977;186:34-41.

5. Strutton DR, Kowalski JW, Glaser DA, Stang PE. US prevalence of hyperhidrosis and impact on individuals with axillary hyperhidrosis: results from a national survey. J Am Acad Dermatol. $2004 ; 51: 241-8$.

6. Tu YR, Li X, Lin M, Lai FC, Li YP, Chen JF, et al. Epidemiological survey of primary palmar hyperhidrosis in adolescent in Fuzhou of People's Republic of China. Eur J Cardiothorac Surg. 2007:31:737-9.

7. Augustin M, Radtke MA, Herberger K, Kornek T, Heigel H, Schaefer I. Prevalence and Disease Burden of Hyperhidrosis in the Adult Population. Dermatology. 2013;227:10-3

8. Park EJ, Han KR, Choi H, Kim DW, Kim C. An epidemiological study of hyperhidrosis patients visiting the Ajou University Hospital hyperhidrosis center in Korea. J Korean Med Sci. 2010;25:772-5.

9. Bragança GM, Lima SO, Pinto Neto AF, Marques LM, Melo EV, Reis FP. Evaluation of anxiety and depression prevalence in patients with primary severe hyperhidrosis. An Bras Dermatol. 2014;89:230-5.

10. Felini R, Demarchi AR, Fistarol ED, Matiello M, Delorenze LM. Prevalência de hiperidrose em uma amostra populacional de Blumenau - SC, Brasil. An Bras Dermatol. 2009;84:361-6.

11. Westphal FL, de Carvalho MA, Lima LC, de Carvalho BC, Padilla R, Araújo KK. Prevalence of hyperhidrosis among medical students. Rev Col Bras Cir. 2011;38:392-7.

12. Lima SO, Aragão JF, Machado Neto J, Almeida KB, Menezes LM, Santana VR. Research of primary hyperhidrosis in students of medicine of the State of Sergipe, Brazil. An Bras Dermatol. 2015;90:661-5.

13. de Andrade Filho LO, Kuzniec S, Wolosker N, Yazbek G, Kauffman P, Milanez de Campos JR. Technical difficulties and complications of sympathectomy in the treatment of hyperhidrosis: an analysis of 1731 cases. Ann Vasc Surg. 2013;27:447-53.

14. Cai SW, Shen N, Li DX, Wei B, An J, Zhang JH. Compensatory sweating after restricting or lowering the level of sympathectomy: a systematic review and metaanalysis. Clinics (Sao Paulo). 2015;70:214-9.

15. Brown AL, Gordon J, Hill S. Hyperhidrosis: review of recent advances and new therapeutic options for primary hyperhidrosis. Curr Opin Pediatr. 2014;26:460-5.

16. Wolosker N, Teivelis MP, Krutman M, de Paula RP, de Campos JR, Kauffman P, et al. Long-term results of oxybutynin treatment for palmar hyperhidrosis. Clin Auton Res. 2014;24:297-303.

17. Wolosker N, Teivelis MP, Krutman M, Campbell TP, Kauffman P, Campos JR,et al. Long-term results of oxybutynin use in treating facial hyperhidrosis. An Bras Dermatol. 2014;89:912-6.

18. Wolosker N, Teivelis MP, Krutman M, de Paula RP, Schvartsman C, Kauffman P, et al. Long-Term Efficacy of Oxybutynin for Palmar and Plantar Hyperhidrosis in Children Younger than 14 Years. Pediatr Dermatol. 201;32:663-7

19. Wolosker N, Teivelis MP, Krutman M, Campbell TP, Kauffman P, Campos JR, et al. Long-term results of oxybutynin use in treating facial hyperhidrosis. An Bras Dermatol. 2014;89:912-6.

20. Teivelis MP, Wolosker N, Krutman M, Kauffman P, Campos JR, Puech-Leão P. Treatment of uncommon sites of focal primary hyperhidrosis: experience with pharmacological therapy using oxybutynin. Clinics (Sao Paulo). 2014;69:608-14.

21. Wolosker N, Krutman M, Campdell TP, Kauffman P, Campos JR, Puech-Leão P. Oxybutynin treatment for hyperhidrosis: a comparative analysis between genders. Einstein (Sao Paulo). 2012;10:405-8.

22. Wolosker N, Munia MA, Kauffman P, Campos JR, Yazbek G, Puech-Leão P. Is gender a predictive factor for satisfaction among patients undergoing sympathectomy to treat palmar hyperhidrosis? Clinics (Sao Paulo). 2010;65:583-6.

23. Wolosker N, Schvartsman C, Krutman M, Campbell TP, Kauffman P, de Campos $\mathrm{JR}$, et al. Efficacy and quality of life outcomes of oxybutynin for treating palmar hyperhidrosis in children younger than 14 years old. Pediatr Dermatol. 2014;31:48-53.
24. Neves S, Uchoa PC, Wolosker N, Munia MA, Kauffman P, de Campos JR, et al. Long-term comparison of video-assisted thoracic sympathectomy and clinical observation for the treatment of palmar hyperhidrosis in children younger than 14 . Pediatr Dermatol. 2012;29:575-9.

25. Wolosker N, Krutman M, Teivelis MP, Paula RP, Kauffman P, Campos JR, et al. Analysis of oxybutynin treatment for hyperhidrosis in patients aged over 40 years. Einstein (Sao Paulo). 2014;12:42-7.

26. de Campos JR, Wolosker N, Takeda FR, Kauffman P, Kuzniec S, Jatene FB, et al. The body mass index and level of resection: predictive factors for compensatory sweating after sympathectomy. Clin Auton Res. 2005;15:116-20.

27. Wolosker N, Krutman M, Kauffman P, Paula RP, Campos JR, Puech-Leão P. Effectiveness of oxybutynin for treatment of hyperhidrosis in overweight and obese patients. Rev Assoc Med Bras (1992). 2013;59:143-7.

MaILING ADDRESS:
Fernanda Alvarenga Estevan
Avenida Doutor Enéas de Carvalho Aguiar, 255
Cerqueira César
05403-000 São Paulo, SP. Brazil
Avenida Albert Einstein, 627/701
Morumbi
05652-900 São Paulo, SP. Brazil
Email: fernanda.aestevan@gmail.com

How to cite this article: Estevan FA, Wolosker MB, Wolosker N, Puech-Leão P. Epidemiologic analysis of prevalence of the hyperhidrosis. An Bras Dermatol. 2017;92(5):630-4. 